\title{
Inappropriate use of the term "cytotoxicity" in scientific literature
}

\author{
Haji Bahadar ${ }^{1}$ and Mohammad Abdollahi ${ }^{1,2^{*}}$
}

We would like to draw the attention of the readers to the inappropriate use of term "cytotoxic" as a substitute for "antineoplastic". This can be noticed in numerous scientific articles, especially those reporting the anticancer properties of certain chemical compounds. For example, there are published studies reporting the anticancer activity of certain drugs/chemicals and the authors have assessed the anticancer activities of some novel drugs against certain target cancers. These investigations have repeatedly involved the term "cytotoxic" instead of "antineoplastic". For instance, recently a report has been published in DARU by Vosough et al. [1] about the anticancer activities of some compounds. In this study, the derivatives of nonsteroidal aromatase inhibitors (triazole analogues) have been synthesized. Then, the newly synthesized derivatives were assessed for anticancer activity against breast cancer cell lines and the results showed that these newly synthesized compounds possess potent cytotoxic activity. Similarly, there are numerous other research reports published either in DARU or elsewhere. These authors also have reported the anticancer activities of different compounds against various cancer cell lines [2-4]. Nonetheless, these authors have assessed the cytotoxicity as a measure of anti-neoplastic potential of certain drugs, but, reporting the effect as "cytotoxic" instead of either "anticancer" or "antineoplastic" might reduce the interest of readers.

Literally cytotoxic refers to "toxic to living cells" while, antineoplastic means inhibiting or preventing the development and spread of neoplasms. For drugs that control or kill only neoplastic cells, the proper term that could describe this inherent activity of drugs is known as antineoplastic or anticancer activity. Moreover, the physiology of a normal cell is entirely dissimilar to that of cancerous cells or neoplasms, having an excessive quantity of free radicals and subsequent oxidative stress [5,6]. Cytotoxicity

\footnotetext{
* Correspondence: Mohammad@TUMS.Ac.Ir

${ }^{1}$ Pharmaceutical Sciences Research Center, International Campus, Tehran University of Medical Sciences, Tehran, Iran

${ }^{2}$ Faculty of Pharmacy, Tehran University of Medical Sciences, Tehran, Iran
}

is a general term used in toxicological studies describing the effect of particular toxins on cell viability [7]. In that respect, there are many compounds that are cytotoxic but not antineoplastic [8]. About anticancer drugs, data can be gathered using cytotoxicity test methods, but that necessarily be described as the antineoplastic or anticancer activity of that particular drug or agent, rather than stating cytotoxicity of anticancer drugs. Because the term cytotoxicity is an umbrella term involving also other toxins which reduce normal cell viability. In simpler words, we may say that a drug with antineoplastic activity possess cytotoxicity. But any cytotoxic agent does not necessarily possess antineoplastic characteristics.

At the end, we are of the opinion that great care must be exercised while using the term cytotoxicity as an alternative to antineoplastic activity, particularly mentioning the activity of anticancer agents. Also, the National Library of Medicine-Medical Subject Headings (MeSH) http://www.nlm.nih.gov/mesh/MBrowser.html does not suggest the term cytotoxic as a substitute for antineoplastic, but the opposite could easily be seen. Furthermore, $\mathrm{MeSH}$ is a very comprehensive controlled scientific terminology helping in proper indexing of the scientific article and books.

Received: 12 February 2015 Accepted: 14 February 2015

Published online: 20 February 2015

\section{References}

1. Vosooghi M, Firoozpour L, Rodaki A, Pordeli M, Safavi M, Ardestani SK, et al. Design, synthesis, docking study and cytotoxic activity evaluation of some novel letrozole analogs. Daru. 2014;22:83.

2. De Vasconcelos A, Campos VF, Nedel F, Seixas FK, Dellagostin OA, Smith KR, et al. Cytotoxic and apoptotic effects of chalcone derivatives of 2-acetyl thiophene on human colon adenocarcinoma cells. Cell Biochem Funct. 2013;31:289-97.

3. Alipour E, Mousavi Z, Safaei Z, Pordeli M, Safavi M, Firoozpour L, et al. Synthesis and cytotoxic evaluation of some new [1,3]dioxolo[4,5-g] chromen-8-one derivatives. Daru. 2014;22:41.

4. Haghighi F, Matin MM, Bahrami AR, Iranshahi M, Rassouli FB, Haghighitalab A. The cytotoxic activities of 7-isopentenyloxycoumarin on 5637 cells via induction of apoptosis and cell cycle arrest in G2/M stage. Daru. 2014;22:3.

5. Abdollahi M, Shetab-Boushehri SV. Is it right to look for anti-cancer drugs amongst compounds having antioxidant effect. Daru. 2012;20:61.
C Biomed Central 
6. Shetab-Boushehri SV, Abdollahi M. Current concerns on the validity of in vitro models that use transformed neoplastic cells in pharmacology and toxicology. Int J Pharmacol. 2012;8:594-5.

7. Riss TL, Moravec RA, Niles AL. Cytotoxicity testing: measuring viable cells, dead cells, and detecting mechanism of cell death. Methods Mol Biol. 2011;740:103-14.

8. Saeidnia S, Abdollahi M. Antioxidants: Friends or foe in prevention or treatment of cancer: The debate of the century. Toxicol Appl Pharmacol. 2013;271:49-63.

Submit your next manuscript to BioMed Central and take full advantage of:

- Convenient online submission

- Thorough peer review

- No space constraints or color figure charges

- Immediate publication on acceptance

- Inclusion in PubMed, CAS, Scopus and Google Scholar

- Research which is freely available for redistribution 